\section{PROPUESTA DE LÍNEAS DE MEJORA DE LA EXPERIENCIA OPERÍSTICA DESDE EL OCIO CREATIVO}

\author{
M. ${ }^{a}$ Luisa Amigo \\ Macarena Cuenca \\ Estudios de Ocio. Universidad de Deusto \\ Avenida de las Universidades 24. \\ 48007 Bilbao (Vizcaya) \\ mlamigo@deusto.es \\ macarena.cuenca@deusto.es
}

\section{THE OPERA EXPERIENCE: SOME IMPROVEMENTS PROPOSED FROM THE PERSPECTIVE OF CREATIVE LEISURE}

\begin{abstract}
This work is framed in an investigation area of creative leisure, which is carried out in the Institute for Leisure Studies of the University of Deusto. Educational programs have, traditionally, been considered a tool to bring opera to new audiences. This article explores the educational initiatives from ten European opera organizations using the content analysis method. We will start from some fundamental principles of the leisure theory and the aesthetic theory, whose mission is to promote more satisfying aesthetic experiences. After evaluating whether these principles are reflected in reality, we will propose some actions that can contribute to furthering the reception process of opera and, thus, improve the operatic experience of the participants in the educational programs.
\end{abstract}

KEY WORDS: Aesthetic leisure; art reception; opera; educational programs.

\section{INTRODUCCIÓN}

La ópera surge a principios del siglo XVII y desde sus comienzos ha constituido una actividad de ocio. Sin embargo, a lo largo de la historia, se han ido produciendo cambios en la vivencia de esta actividad por parte del público. Así, en la sociedad tradicional, la ópera se vivía como una fiesta, con un ambiente que nadie se quería perder. En ella era tan importante lo que ocurría en el escenario como cualquier otra actividad de ocio que podía tener lugar entre el público al tiempo de la representación, como por ejemplo, partidas de cartas, charlas entre amigos, etc. (Alier, 2004). Con la industrialización, acudir a la ópera se convirtió en una forma de ostentación y exhibicionismo social y en el siglo XXI, el tiempo de una sociedad vivencial, el público
RESUMEN: Este trabajo se enmarca en un área de investigación de ocio creativo, que se lleva a cabo en el Instituto de Estudios de Ocio de la Universidad de Deusto. Los programas didácticos han constituido, tradicionalmente, una herramienta para acercar la ópera a nuevos colectivos. En este artículo analizaremos las iniciativas didácticas de una decena de organizaciones operisticas europeas utilizando la técnica de análisis de contenidos. Para ello, partiremos de unos principios teóricos procedentes de la teoría del ocio y la teoría de la estética, cuya misión es favorecer experiencias de ocio estético más satisfactorias. Tras evaluar si dichos principios tienen su reflejo en la realidad, propondremos algunas líneas de intervención que puedan contribuir a favorecer el proceso de recepción de la ópera y que, de esta manera, mejoren la experiencia operística de los participantes en los programas didácticos.

PALABRAS CLAVE: Ocio estético; recepción del arte; ópera; programas didácticos.

acude a la ópera, fundamentalmente, para disfrutar de la representación. Así, hoy en día, la ópera como experiencia de ocio se enmarca principalmente en la vertiente recreativa de la dimensión creativa del ocio (Cuenca, 2000, 2004).

Diversos autores defienden que el proceso re-creativo es un proceso activo que, a través de un esfuerzo creador, trata de hacer realidad el encuentro con la obra y buscar el disfrute (Amigo, 2000, 2008; Eco, 1979; López Quintás, 2005). A lo largo de esa búsqueda del disfrute se pueden llegar a producir experiencias óptimas o estados de flujo (Csikszentmihalyi, 2008), especialmente cuando se comiencen a desarrollar unas habilidades de escucha y gracias a un proceso de retroalimentación inmediata, la 
persona sea consciente de ellas y pueda ir superando retos cada vez mayores. Según Davis (1988, 48-51), en las artes escénicas los retos se presentarian en forma de grandes cantidades de información sensorial y las habilidades de los espectadores harían referencia a su propia capacidad de percepción. Así, si un miembro de la audiencia percibe menos de la representación de lo que podría asimilar, se aburrirá, mientras que si ocurre al revés, aparecería en él un sentimiento de ansiedad o frustración.

Las organizaciones operísticas parecen tener claro que la formación en la ópera y su disfrute están relacionados y, por ello, no es casualidad que sus programas didácticos estén muy desarrollados. En este artículo nos acercaremos a este tipo de programas y trataremos de evaluarlos desde una perspectiva teórica. Posteriormente, a la luz de los resultados obtenidos, propondremos posibles líneas de acción que los teatros de ópera podrían incorporar a sus proyectos didácticos con el objetivo de favorecer el proceso de recepción de los espectadores y, por tanto, favorecer que las experiencias operísticas sean más satisfactorias.

\section{FundAMENTACIÓN TEÓRICA}

Este apartado sienta las bases para poder, posteriormente, analizar la realidad. Tras desgranar el proceso de recepción de la ópera desde la disciplina de la estética, presentaremos una serie de principios fundamentales procedentes de la pedagogía del ocio y de la estética que favorecerán una experiencia operística satisfactoria.

\subsection{La recepción de la ópera como experiencia de ocio estético}

La Estética como disciplina filosófica se ha ocupado de la experiencia estética recreadora. Autores como Gadamer (1996), Dewey (1949), Dufrenne (1982), Jauss (1986), Plazaola (1991), López Quintás (1998), Jiménez (1998), Molinuevo (1998) y otros han analizado en qué consiste, destacando sus rasgos diferenciadores. Los fenómenos estéticos proporcionan emoción, gozo y conocimiento. Los investigadores coinciden en privilegiar la actitud como un elemento que permite diferenciar el ámbito estético. La actitud es la disposición de la persona, su manera de plantear la apertura hacia la propuesta estética. Tiene una función primordial e, incluso, un autor como R. Jauss escribe que "la experiencia estética se realiza al adoptar una actitud ante su efecto estético, al comprenderla con placer y al disfrutarla comprendiéndola" (Jauss, 1986, 1314). Por lo tanto, favorecer esta actitud debería ser un elemento clave para facilitar el acercamiento a la ópera. La actitud se inscribe en un horizonte de libertad, es decir, el sujeto la elige libremente sin buscar otra meta. Como hemos apuntado, en la reflexión del ocio nos referimos al autotelismo o experiencia que tiene un fin en sí misma. La experiencia receptora de la ópera parte de la actitud, la elección libre y el autotelismo para conseguir la satisfacción y el goce. Destacamos, a continuación, los factores que pueden conducir a esta meta.

\subsubsection{Recreación: participación y descubrimiento}

La experiencia de ocio estético se inicia en el asombro. Los filósofos y los artistas han destacado el valor de este impacto para vivir estéticamente (Plazaola, 1991, 301). La mirada de asombro rompe la atención cotidiana y la concentra en el objeto estético. ¿Cuál es el objeto que condensa el interés del receptor? La respuesta se concreta en lo sensible. Es la dimensión sensible la que llega a la mirada, a los sentidos. Ejerce inmediatamente un efecto en la medida que concentra al contemplador en el fenómeno y le paraliza como persona práctica. La experiencia estética le transforma en mirada, en atención al objeto que le reclama.

Esta fase inicial puede considerarse como ruptura del ritmo cotidiano y es una emoción estimulante que invita a continuar el proceso. En la representación de la ópera la oscuridad del ámbito de los espectadores ayuda a afincar la mirada en el asombro y favorece el deseo de que la experiencia continúe.

La reflexión estética reconoce en la actualidad que la recepción del arte es creatividad, activamente participante e interactuante (López Quintás, 1998; Eco, 1979). La experiencia estética supone una tarea de reconstrucción e integración que involucra plenamente al receptor; no es una actitud pasiva y quieta sino de participación y coejecución. Esta apropiación puede favorecerse y se realiza en el espacio interior que permite el discernimiento y la valoración (Jiménez, 1998). El receptor tiene que ayudar a crear su propia experiencia, tiene que constituir el objeto 
sobre el que va a desplegar su creatividad y en el que va a encontrar una fuente de disfrute. Si la experiencia del artista se condensa en la forma que crea, la experiencia del receptor se concreta en una participación co-creadora en la obra dada. En esta línea Jauss (1986), Gadamer (1996) y otros autores han insistido en la participación como complemento necesario de la obra. En la experiencia de ocio estético el ser humano tiene un campo de posibilidades para encauzar su capacidad creadora y co-creadora.

\subsubsection{Dimensiones del proceso de recreación}

El proceso de recreación puede ser comprendido en fases que no tienen que ser entendidas cronológicamente. Hospers lo hace sintetizándolas en tres dimensiones que se han traducido como: superficie estética, forma estética y valores vitales. Podemos comprenderlas como un acercamiento sensible, formal y de sentido. La primera se centra en la percepción sensible; la segunda, a través de ésta, responde a la forma y la tercera, basada en las anteriores, en el sentido o en el significado. Los tres aspectos están interrelacionados. Comprender uno sin el otro ofrece una imagen distorsionada de la experiencia.

La apreciación de las obras de arte no se limita a los valores de superficie o los formales. Gozamos del arte en la medida en que nos ofrece una imagen de la vida y es un símbolo de nuestra historia, de nuestra existencia, personal o colectiva, en las múltiples facetas y concreciones que los artistas realizan (Hospers, 1980, 28-30). Reducir las experiencias, como han hecho algunos teóricos, a los valores formales, es una actitud purista que nos impide disfrutar experiencias en el ámbito de los valores humanos o de los valores vitales, en expresión de Hospers. Este aspecto nos conduce a resaltar el ámbito de comprensión de la experiencia de la obra.

La comprensión es un proceso que parte de un acto de reconocimiento intuitivo, rebasa lo sensible y alcanza lo inteligible; conlleva un juicio de identidad acompañado de placer o gozo intelectual. Éste proviene de la comprensión o reconocimiento. El receptor acoge la obra y esa experiencia es, al mismo tiempo, una profundización en su propia autocomprensión (Gadamer, 1977). La obra reclama y habla de una forma presente y simultánea. Los receptores integran ese diálogo en su comprensión del mundo y en su propia autocomprensión.
Estas dimensiones conducen a gozar con la propuesta estética. La satisfacción surge en la vivencia actualizada de la obra y no en un hipotético regreso al tiempo en que fue creada. El espectador experimenta el disfrute en relación con él, como persona en el mundo que le ha tocado vivir. Puede gozar con obras realizadas hace mucho tiempo, pero la lectura que hace de ellas debe Ilevarla a cabo desde su presente. Éste es un primer aspecto que se debe tener en cuenta. En segundo lugar, el goce se intensifica al observar el placer de la comprensión que el objeto proporciona. En este caso el arte ofrece un mundo condensado que el autor ha configurado intencionalmente en forma. Su recepción es una tarea compleja $y$, a veces, difícil, que conduce a adentrarse en los valores sensibles, formales y de sentido. La obra es un microcosmos que invita a participar. Este fenómeno es, sin duda, una fuente específica de placer, como señaló Aristóteles y, recientemente, Jauss (1986).

El proceso de recepción se vive en el tiempo que dura la representación. Pero como toda experiencia tiene un espacio anterior que puede ser aprovechado para favorecer que la vivencia en la sala sea más rica. Puede tener también una consecuencia posterior por el impacto que deja en el espectador. Podría entenderse, incluso, desde una perspectiva ética, abriéndose más allá de la experiencia vivida en el teatro e invitando a la consecución de una vida más digna y justa que la observada en la escena. Quizá sea éste el beneficio más ambicioso y, a la vez, más fecundo del arte.

La aplicación de estos factores tiene que orientarse al logro de experiencias de ocio satisfactorias. Especialmente en este ámbito del ocio creativo y, concretamente, de la ópera, la experiencia debe ser lo más placentera posible. La participación personal ayudará al ajuste entre las expectativas de los sujetos y la experiencia real de la representación. Las diferentes fases del proceso tendrán que tener en cuenta que la preparación tiene que hacer compatible la diversión con la formación. Todo el proceso debería ser gratificante para la persona que lo realiza.

\subsection{Principios educativos que sustentan las acciones formativas en el ámbito del ocio}

El apartado anterior ha puesto de manifiesto el proceso temporal de la experiencia estética, destacando la actitud personal, la participación, el descubrimiento y el goce o sa-

ARBOR Vol. 188754 marzo-abril [2012] 427-440 ISSN: 0210-1963 
tisfacción. Como experiencia de ocio el proceso de recepción de la ópera se basa en los principios del ocio, es decir, vivencia, libertad, satisfacción y autotelismo. Aquéllos se sustentan en éstos, razón que explica las líneas confluyentes.

Nos proponemos ahora apuntar los factores educativos que facilitarian su realización en la práctica y que subrayan principios educativos, tomando como punto de referencia la pedagogía del ocio (Cuenca, 2004). El punto de partida es la concepción del ocio como experiencia y ámbito de desarrollo humano. La comprensión del ocio desde la libertad, la satisfacción y el autotelismo orientan un posicionamiento pedagógico basado en principios consecuentes. La finalidad sería el logro de experiencias de ocio valiosas en sí mismas, que generen la continuidad de un ocio serio. Sin la pretensión de entrar en la planificación de objetivos y actividades, recogemos algunos principios fundamentales que se deberian considerar en cualquier programa. Éstos serian la personalización, la continuidad, el desarrollo, la inclusión y la solidaridad.

Personalización. Significa que cada persona con su peculiaridad es el sujeto de la experiencia. La persona debe ser el referente de cualquier acción pedagógica que trate de favorecer la experiencia de ocio. También desde la reflexión estética acabamos de observar cómo el proceso tanto de percepción como de comprensión es personal y diferenciado. Este principio debe realizarse haciendo compatible el ocio individual y el social. No sólo cuenta el grupo, sino cada persona y requiere acciones que tengan en cuenta las diferencias personales. Este principio se vincula a la participación que hemos visto desde la estética y llama la atención sobre la implicación personal. La experiencia de ocio se genera en un espacio de participación en el que la persona pueda desarrollar sus capacidades físicas, mentales y emocionales. La experiencia desde el pensamiento estético se comprende coparticipada y activa. La participación reclama acciones que alienten la comunicación e inciten a la recepción activa favoreciéndola como una aventura de descubrimientos (Eco, 1979).

Continuidad. La educación del ocio es un proceso continuo que debe ser entendido a lo largo de la vida. Significa que debe encauzarse hacia acciones educativas no casuales, sino proyectadas en el tiempo. Requiere una coherencia con otras facetas formativas e induce a dar continuidad a la formación inicial. La reflexión sobre el ocio destaca el carácter de proceso de toda experiencia valiosa. Lo mismo hemos visto desde la estética. Ello significa que toda experiencia es un proceso que se inicia cuando se planifica, continúa cuando se realiza y culmina cuando se rememora. El proceso de una experiencia es imagen de la continuidad de desarrollo de un ocio serio a lo largo de la vida.

Desarrollo. La educación del ocio ha de favorecer el desarrollo integral de la persona a partir de conocimientos, actitudes, habilidades y valores de ocio. Éste es un objetivo a largo plazo. Orientándolo a la educación de la ópera reafirma el proceso experiencial, destacando el interés formativo de la planificación, el desarrollo y la evaluación de las experiencias de ocio. Este principio está vinculado con el anterior, ya que ambos aluden a un proceso.

Inclusión. La inclusión se vincula con un sistema de valores de respeto a todas las personas. Lleva consigo la utilización de espacios, recursos y equipamiento para todos, enfatizando la pertenencia a la comunidad y el beneficio de todos. Está vinculado con la participación y la equiparación de oportunidades.

Solidaridad. Consiste en el reconocimiento práctico de la obligación natural que todas las personas tenemos de contribuir al bienestar común. Responsabilidad, respeto y sostenibilidad serían pilares básicos de este principio.

No desarrollamos más estos dos últimos principios por ser básicos en la vida social.

\subsection{Resumen de principios teóricos procedentes de la pedagogía del ocio y de la teoría de la estética}

Una vez expuestos en detalle los principios educativos y estéticos, nos proponemos ahora ofrecer una visión global de los mismos. Estos principios pueden ayudar a pensar cualquier acción educativa que quiera favorecer la experiencia de ocio valiosa, implicando a las personas, facilitando el despliegue de sus expectativas y desarrollando sus conocimientos y valores. Una experiencia de ocio estético valiosa será la mejor apuesta para que los sujetos opten por un ocio serio, de compromiso a largo plazo con la ópera. Todos ellos orientan en determinadas pautas de intervención educativa. La tabla que aparece a continuación resume todos ellos. 
TABLA 1. RELACIÓN DE PRINCIPIOS Y LÍNEAS DE INTERVENCIÓN EDUCATIVAS FAVORECEDORAS DE LA RECEPCIÓN DE LA EXPERIENCIA OPERISTICA

\begin{tabular}{|c|c|c|}
\hline Ámbito & Principios & Líneas de intervención educativas \\
\hline \multirow[t]{14}{*}{$\mathrm{OClO}$} & VIVENCIA & Promover experiencias de aprendizaje: \\
\hline & \multirow{3}{*}{$\begin{array}{l}\text { Promueve un ocio tanto activo como contemplativo en todas sus } \\
\text { dimensiones (lúdica, creativa, festiva, ambiental-ecológica y so- } \\
\text { lidaria). }\end{array}$} & - Diversas \\
\hline & & - Globales (todo se relaciona con todo) \\
\hline & & $\begin{array}{l}\text { - Integradas (relacionadas con el sentido de la vida y los valores } \\
\text { de cada uno) }\end{array}$ \\
\hline & LIBERTAD & Promover experiencias de aprendizaje: \\
\hline & \multirow{3}{*}{$\begin{array}{l}\text { Se desarrolla en ausencia de coacción y tiene también un sentido } \\
\text { positivo de capacidad, es decir, de elegir en cada momento el modo } \\
\text { de obrar que se considere mejor entre las distintas posibilidades } \\
\text { que la situación ofrece. }\end{array}$} & - Sin coacción \\
\hline & & - Sin direccionismo ni paternalismo \\
\hline & & - Que estimulen y abran caminos de desarrollo personal \\
\hline & SATISFACCIÓN & Promover experiencias de aprendizaje: \\
\hline & \multirow{2}{*}{$\begin{array}{l}\text { No está reñida con el esfuerzo y se materializa cuando se produce } \\
\text { un ajuste entre las expectativas de la persona y su vivencia de } \\
\text { ocio real. }\end{array}$} & $\begin{array}{l}\text { - Gratificantes tanto en el proceso de aprendizaje como en sus } \\
\text { resultados }\end{array}$ \\
\hline & & $\begin{array}{l}\text { - Que tiendan a ajustar las expectativas de los participantes y } \\
\text { la realidad }\end{array}$ \\
\hline & AUTOTELISMO & Promover experiencias de aprendizaje: \\
\hline & \multirow{2}{*}{$\begin{array}{l}\text { Contrario al utilitarismo. Caracteriza a la experiencia de ocio como } \\
\text { un fin en sí misma. }\end{array}$} & - Valiosas en sí mismas \\
\hline & & $\begin{array}{l}\text { - Que supongan un reto de autosuperación respecto a experien- } \\
\text { cias anteriores }\end{array}$ \\
\hline \multirow[t]{19}{*}{ EDUCACIÓN } & PERSONALIZACIÓN & Promover experiencias de aprendizaje: \\
\hline & \multirow{3}{*}{$\begin{array}{l}\text { Promueve el establecimiento de objetivos de aprendizaje grupales e } \\
\text { individuales, que partan del conocimiento de cada persona a quien } \\
\text { se dirige la acción educativa. Según este principio, cada persona } \\
\text { debe buscar los medios para aprovechar sus posibilidades de ocio. }\end{array}$} & - Que partan de los sujetos \\
\hline & & - Que tengan objetivos individuales y grupales \\
\hline & & - Que favorezcan la personalización \\
\hline & CONTINUIDAD & Promover experiencias de aprendizaje: \\
\hline & \multirow{2}{*}{$\begin{array}{l}\text { Promueve la acción educativa a lo largo de la vida, la coherencia } \\
\text { entre las distintas experiencias educativas y la continuación en los } \\
\text { objetivos y procedimientos. }\end{array}$} & $\begin{array}{l}\text { - Que den continuidad a la formación inicial para que conduzcan } \\
\text { a un futuro deseado }\end{array}$ \\
\hline & & - Que eviten objetivos y procedimientos opuestos \\
\hline & DESARROLLO & Promover experiencias de aprendizaje: \\
\hline & \multirow{4}{*}{$\begin{array}{l}\text { Promueve el desarrollo integral de la persona a partir de conoci- } \\
\text { mientos, actitudes, habilidades y valores de ocio con el objetivo de } \\
\text { que ésta aumente su calidad de vida mediante el ocio y la auto- } \\
\text { organización. Defiende el interés tanto de la planificación como } \\
\text { del desarrollo y la evaluación de la acción formativa. }\end{array}$} & - Estimulantes y que despierten entusiasmo \\
\hline & & - Que inicien e introduzcan a las personas en el mundo de la ópera \\
\hline & & - Que ofrezcan y pongan a disposición la experiencia operística \\
\hline & & $\begin{array}{l}\text { - Que aconsejen y ayuden, proporcionando consejos y aclaracio- } \\
\text { nes, siempre que sea necesario }\end{array}$ \\
\hline & INCLUSIÓN & Promover experiencias de aprendizaje: \\
\hline & \multirow[t]{2}{*}{$\begin{array}{l}\text { Asume que la convivencia y el aprendizaje en los grupos con dife- } \\
\text { rencias es la mejor forma de beneficiar a todos y cada uno. }\end{array}$} & $\begin{array}{l}\text { - Que fomenten la participación de todas las personas de la } \\
\text { comunidad }\end{array}$ \\
\hline & & - Que fomenten la equiparación de oportunidades \\
\hline & SOLIDARIDAD & Promover experiencias de aprendizaje: \\
\hline & \multirow{3}{*}{$\begin{array}{l}\text { Se asienta sobre las ideas centrales de responsabilidad, respeto y } \\
\text { sostenibilidad. }\end{array}$} & - Que se adapten a las necesidades y demandas locales \\
\hline & & - Que promuevan la conciencia de preservación \\
\hline & & - Que promuevan un uso sostenible de espacios y recursos \\
\hline
\end{tabular}


TABLA 1. RELACIÓN DE PRINCIPIOS Y LÍNEAS DE INTERVENCIÓN EDUCATIVAS FAVORECEDORAS DE LA RECEPCIÓN DE LA EXPERIENCIA OPERÍSTICA (CONTINUACIÓN)

\begin{tabular}{|c|c|c|}
\hline Ámbito & Principios & Líneas de intervención educativas \\
\hline \multirow[t]{15}{*}{ ESTÉTICA } & ACTITUD PERSONAL & Promover experiencias de aprendizaje: \\
\hline & \multirow[t]{2}{*}{ Disposición libre de la persona abierta a la propuesta estética. } & - Que favorezcan la atención centrada hacia el objeto estético \\
\hline & & - Que faciliten una relación empática con la obra \\
\hline & PARTICIPACIÓN & Promover experiencias de aprendizaje: \\
\hline & \multirow{2}{*}{$\begin{array}{l}\text { Proceso de coejecución y apropiación del objeto que la persona } \\
\text { lleva a cabo en la experiencia estética. }\end{array}$} & - Que potencien la implicación activa del receptor \\
\hline & & - Que inciten al discernimiento \\
\hline & DESCUBRIMIENTO & Promover experiencias de aprendizaje: \\
\hline & \multirow[t]{2}{*}{$\begin{array}{l}\text { Reconocimiento de elementos sensibles, formales y de sentido } \\
\text { mediante la participación. }\end{array}$} & $\begin{array}{l}\text { - Que faciliten la atención de la persona hacia los factores sensi- } \\
\text { bles, formales o estructurales, de significado o sentido }\end{array}$ \\
\hline & & - Que transmitan el patrimonio que supone la obra \\
\hline & COMPRENSIÓN & Promover experiencias de aprendizaje: \\
\hline & \multirow[t]{2}{*}{$\begin{array}{l}\text { Proceso de integración de los elementos descubiertos y de actua- } \\
\text { lización en el presente. }\end{array}$} & $\begin{array}{l}\text { - Que favorezcan la actualización de la obra y su integración en } \\
\text { el receptor }\end{array}$ \\
\hline & & - Que converjan en la valoración \\
\hline & SATISFACCIÓN & Promover experiencias de aprendizaje: \\
\hline & Goce en el proceso y por la actualización del objeto estético. & - Que aporten razones para el gozo \\
\hline & & - Que sea en sí mismo un proceso de disfrute \\
\hline
\end{tabular}

Fuente: Elaboración propia a partir de Cuenca (2004, 251-260) y Amigo (2008).

\section{ANÁLISIS dE LA REALIDAD}

A lo largo de este apartado, revisaremos en profundidad las características de los programas didácticos correspondientes a las organizaciones operísticas analizadas. Pero, antes de adentrarnos en ese detalle, es interesante clarificar quiénes son dichas organizaciones y cuál ha sido la metodología utilizada.

\subsection{Metodología}

El tipo de análisis escogido ha sido el denominado "Análisis de contenido" (Andréu, 2001; Malhotra, 2004). Las organizaciones de ópera europeas han constituido la unidad de muestreo. Para cada una de ellas hemos analizado, con la ayuda de una ficha de contenidos, sus programas didácticos y actividades complementarias publicadas en sus páginas web. El muestreo aplicado ha sido el muestreo por juicio, que, en nuestro caso, se ha fundamentado en el tipo de políticas que dichas organizaciones están siguiendo. Debido a que este tipo de acciones están muy relacionadas con la generación de interés y el desarrollo de audiencias, hemos procedido a considerar aquellas organizaciones más activas en cuanto a interés por captar y atender nuevos públicos. En concreto, las diez organizaciones seleccionadas han sido las siguientes: Badisches Staatstheater Karlsruhe (Karlsruhe-Alemania); ABAO (Bilbao-España); Gran Teatre del Liceu (BarcelonaEspaña); Teatro Real de Madrid (Madrid-España); Finnish National Opera (Helsinki-Finlandia); Opéra de Paris (ParísFrancia); Teatro AllaScala (Milán-Italia); De Nederlandse Opera (Ámsterdam-Paises Bajos); Opera North (Leeds-Reino Unido) y Royal Opera House (Londres-Reino Unido).

\subsection{Análisis de los programas didácticos de las organizaciones operísticas seleccionadas}

Hemos estructurado nuestro análisis de los programas didácticos en tres grandes apartados diferenciados en fun- 
ción del público al que se dirigen. En primer lugar, hemos agrupado aquellas iniciativas que consideramos que están orientadas al público en general; en segundo lugar, aquellas que lo están a centros educativos (ya sean colegios o universidades) $y$, por último, las que van dirigidas a familias. Hemos considerado únicamente aquellas iniciativas que tratan de favorecer una experiencia operística lo más satisfactoria posible. Conscientemente, hemos dejado al margen todas aquellas actividades orientadas a dar notoriedad a la organización operística y a otorgar a la ópera un valor de contexto'.

\subsubsection{Iniciativas dirigidas al público en general}

Las casas de ópera son conscientes de que una mayor preparación de la ópera suele desembocar en una experiencia escénica más satisfactoria. En el año 2001, la red de óperas francesas, Réunion des opéras de France (ROF), llevó a cabo un estudio sobre el público de la ópera en Francia y concluyó que el 69\% de los espectadores franceses preparaba su salida a la ópera, investigando sobre la obra, su contexto musical, histórico, político y sobre la vida del compositor. La investigación señalaba que, gracias a este trabajo personal del espectador, éste iba consolidando su propio gusto lírico y esto le facilitaba la selección de espectáculos posteriores. Según Doublet $(2001,2003)$, si el recién iniciado no tiene acceso a este tipo de información, se desanimará y abandonará el camino que le llevará una vez más a la ópera. Sin embargo, esta preparación implica una inversión de tiempo adicional a la del espectáculo, que convierte esta variable en una de las principales barreras de acceso a la ópera y que explica que, en el año 2001, en Francia el público estuviera compuesto por un $42 \%$ de personas inactivas, es decir, de aquellas personas con una mayor disponibilidad de tiempo.

Por todo lo anterior, las organizaciones operísticas tratan de facilitar al espectador la preparación de ópera de forma que, gracias a una serie de herramientas, la inversión de tiempo necesaria sea la menor posible. Como iremos viendo a lo largo de este apartado, las herramientas a las que nos referimos se materializan en charlas introductorias, información específica ofrecida en diferentes formatos y soportes, cursos o encuentros con artistas.

En primer lugar, una de las actividades más extendidas entre los teatros es la charla informativa previa a la re- presentación de la ópera. El 100\% de las organizaciones seleccionadas realizan charlas en torno a cada uno de los títulos de ópera. El 40\% de ellas lo realiza un día puntual, diferente a las fechas de las funciones, mientras que el $60 \%$ restante realiza las charlas cada dia que hay función y éstas se suelen realizar unos 45 minutos antes del comienzo de la representación en alguna sala del teatro. Opéra de Paris, por ejemplo, organiza originales desayunos en Studio Bastille, en los que puede llegar a ofrecer un concierto de música de cámara, una proyección o un encuentro con un artista. Asimismo, organiza encuentros literarios en torno a un tema de la temporada lírica o conferencias en las que pueden participar gran parte del reparto al completo o responsables de la producción. Un caso destacable es el del Teatro Real de Madrid, que graba un vídeo de la charla informativa y lo publica en su página web para que esté disponible a todo el mundo. Internet se está convirtiendo, cada vez más, en un recurso fundamental para la tarea de crear interés por la ópera.

\section{En segundo lugar, una forma de facilitar a los espectado-} res la preparación de una ópera es ofrecerles un amplio abanico de información relacionado con el título de ópera, de forma que sea cada persona quien seleccione lo que más le interese. Así, por ejemplo, mientras alguien pueda estar más interesado en la escenografía, otro pudiera estarlo en la música, o en el texto, o el contexto, etc. En cualquier caso, como hoy en día la búsqueda natural de información es a través de internet, lo lógico es que ésta sea la principal fuente de investigación para el espectador, sin perjuicio de que la información básica se encuentre recogida también en el programa de mano. Además, internet tiene la ventaja de soportar no sólo texto, sino formatos audiovisuales, de manera que es posible escuchar fragmentos de la ópera o visualizar determinadas producciones. La Royal Opera House, que defiende como uno de sus pilares la educación a lo largo de la vida, considera vitales los recursos audiovisuales y por ello ha apostado por las nuevas tecnologías, convirtiéndose en líder en este aspecto entre las casas de ópera europeas. La organización londinense pone a disposición de todos los internautas una multitud de vídeos y podcasts que recogen tanto fragmentos de óperas como vídeos didácticos que muestran el trabajo realizado detrás de los escenarios, entrevistas con artistas o charlas explicativas. Los materiales, además de estar disponibles en la página web, también lo están en un canal de YouTube y en iTunes, de forma que puedan ser descargados y utilizados en dispositivos móviles.

ARBOR Vol. 188754 marzo-abril [2012] 427-440 ISSN: 0210-1963 
En tercer lugar, dentro de las iniciativas orientadas al desarrollo de audiencias, tampoco es extraño encontrar ofertas de cursos dirigidos al público en general, como por ejemplo, cursos de larga duración ofertados por las organizaciones operísticas o encuentros con artistas. Así, el Teatro Real de Madrid ofrece cursos de historia y apreciación de la ópera, organizados en 12 sesiones y Opéra de París ofrece encuentros con artistas, posibilitando la participación y el debate con el público, utilizando para ello la figura de un animador.

\subsubsection{Iniciativas dirigidas a centros educativos}

Uno de los grupos de interés más habituales para las organizaciones operisticas son los centros educativos, bien sea colegios o universidades. En el primer caso, que es el que cuenta con una mayor tradición de los dos, los programas didácticos se suelen integrar dentro del currículo escolar, constituyendo una actividad obligatoria para los alumnos. En el caso de las universidades, por el contrario, las actividades suelen ser opcionales y estar enmarcardas en cursos o créditos de libre elección. Al analizar las iniciativas dirigidas a los distintos tipos de centro hemos distinguido entre las que son específicas a cada uno y las que son comunes a los dos (asistencia a ensayos y visitas a producciones).

Iniciativas dirigidas a colegios

Los programas didácticos dirigidos a colegios están muy extendidos y esto se refleja en nuestra muestra, ya que el $100 \%$ de las organizaciones seleccionadas cuentan con programas dirigidos a estudiantes de primaria o secundaria. Las actividades son variadas y van desde sesiones puntuales en el aula hasta programas a más largo plazo.

Una de las iniciativas que cada vez resulta más habitual son las funciones escolares, que se llevan a cabo en horario de mañana y no están abiertas a todo el mundo, sino únicamente a grupos de colegios. Consisten en títulos de ópera adaptados o compuestos expresamente para el público infantil. Estas representaciones suelen durar en torno a una hora y utilizan recursos para facilitar la comprensión del público (idioma local, vocabulario sencillo, etc.), así como para llamar su atención (decorados y vestuario Ilamativos, alguna anécdota graciosa, etc.). Normalmente, llevan asociada una guía didáctica para que los profesores puedan trabajar la obra con sus alumnos con anterioridad a la excursión al teatro.

Dentro de los recursos más innovadores y que, poco a poco, van calando en un número cada vez mayor de organizaciones, están las sesiones didácticas participativas, donde son los propios alumnos, normalmente estudiantes de secundaria, quienes a lo largo de todo un curso preparan su propia función de ópera. Se trata de proyectos multidisciplinares, donde los alumnos trabajan la creatividad, la capacidad de expresión y comunicación y otra serie de habilidades, ya que se encargan de preparar absolutamente todos los elementos de una ópera: el libreto, la música y canciones, la acción teatral, la escenografía, la caracterización, la dirección, la iluminación, etc. Habitualmente, este tipo de proyectos lleva aparejada una formación de profesores, que son quienes, realmente, llevan el peso del proyecto. Además, suele existir apoyo por parte de la organización operística, quien proporciona ayuda, especialmente cuando se acerca el momento de la representación de la ópera a los padres y amigos. Existen casos en los que la ópera se representa en el propio colegio o casos en los que el teatro cede un auditorio para que diversos colegios realicen sus representaciones.

De nuestras organizaciones, el 60\% de ellas realiza de una u otra forma este tipo de proyectos. Así, por ejemplo, en España, tanto Barcelona como Madrid impulsan este tipo de proyectos y la Finnish National Opera declara que, a pesar de ser una iniciativa económicamente cara, merece la pena mantenerla debido a los excelentes resultados que produce. En el entorno anglosajón, tanto Opera North como Royal Opera House apuestan por este modelo y consideran que la participación de los alumnos es esencial para conseguir una verdadera implicación. Estas organizaciones, además, están tendiendo a organizar proyectos de más larga duración incluso que un curso académico, ya que se han dado cuenta de que cuanto más largos sean los períodos de contacto con los alumnos, mejores resultados se alcanzan y el impacto conseguido es mayor.

Determinadas organizaciones, comprometidas con la inclusión, cuentan con proyectos para colectivos determinados, como, por ejemplo, inmigrantes o discapacitados. Asi, por ejemplo, la Finnish National Opera organizó en 2008 un proyecto destinado a niñas inmigrantes, con una serie de talleres sobre La Cenerentola². La misma organi- 
zación también llevó a cabo un ensayo especial de La Bella Durmiente para niños y adolescentes discapacitados de Helsinki, así como para un grupo de adultos rehabilitados de enfermedades mentales. Otra organización comprometida con este tipo de colectivos es Opera North, en Leeds, que cuenta con un proyecto destinado a adolescentes de entre 10 y 14 años con el sindrome de Asperger. El proyecto se lleva a cabo durante los meses de enero a marzo y consiste en la realización de unos talleres semanales en los que los niños acaban creando su propia composición de teatro musical.

Una vertiente interesante de los proyectos didácticos es la importancia que, cada vez más, está cobrando la formación de profesores, erigiéndose éstos como personas clave dentro del proceso formativo de escolares. Las organizaciones operísticas son conscientes de que es muy rentable mimar la relación con los profesores, ya que son ellos los que tienen la llave para estimular y sensibilizar a sus alumnos, así como despertar su interés por el mundo de la lírica. Por otro lado, y a efectos prácticos, de esta forma, el alcance de las actuaciones de la organización es mucho mayor.

De la muestra seleccionada, el 80\% de las organizaciones realizan algún tipo de sesión formativa a los profesores de los centros con los que colaboran. El Badisches Staatstheater Karlsruhe, por ejemplo, desde una posición más modesta, realiza un encuentro anual con profesores, donde les presentan el programa de la temporada y los materiales didácticos que ponen a su disposición $y_{\text {, por }}$ otro lado, provocan la comunicación con ellos, solventando las posibles dudas que pueda haber.

Las organizaciones que cuentan con proyectos de ópera en el aula, como ya hemos mencionado previamente, también cuentan con formación específica para el profesorado, de forma que puedan llevar a cabo el proyecto. Otro ejemplo distinto sería Opéra de París, que tiene un acuerdo con facultades de magisterio para colaborar en la formación de maestros, bien sea en su formación inicial o en actividades de formación continua. La ópera de Ámsterdam o la de Leeds también realizan sesiones formativas para profesores, dirigidas a profesores que quieran desarrollar sus habilidades creativas y musicales para aplicarlas en clase. Muchos de estos cursos ofertados se cobran, pero aun así, tienen un gran éxito y cada vez se están implantando con más fuerza.
Iniciativas dirigidas a universidades

En el ámbito universitario, las posibilidades de acción son relativamente amplias, ya que las iniciativas pueden ir dirigidas tanto a estudiantes jóvenes como a gente más mayor que acude a la universidad a cursos especialmente diseñados para ellos. De la muestra analizada, un $80 \%$ de las organizaciones mantiene acuerdos con universidades, bien sea a través de cursos, charlas, grupos de discusión o incluso visualización de representaciones en pantallas gigantes o representaciones en vivo.

Resulta de gran interés la iniciativa "Opera Oberta" impulsada por el Liceu. "Opera Oberta" consiste en un curso universitario de iniciación a la ópera, cuya originalidad reside en la transmisión en directo de diversos títulos de la temporada del Liceu, y en la asistencia, de forma simultánea, de unos 2.000 alumnos universitarios repartidos por 50 universidades de todo el mundo, como si estuviesen ocupando una de las butacas del teatro. El programa se completa con una presentación previa de unos diez-quince minutos, grabada en alguna de las universidades colaboradoras, y con un portal en la Red con informaciones complementarias sobre la ópera que se transmite. También es curioso el programa Opera-Universidad ofrecido por Opéra de París en su página web, que consiste en un programa a la carta para grupos de entre 20 y 40 personas. La organización propone que es posible organizar visitas a cualquiera de los dos teatros (Palais Garnier y Opéra Bastille) o diversos tipos de encuentros con personal de la organización, con equipos de producción o con artistas.

Iniciativas comunes a los colegios y universidades

Dos actividades muy extendidas entre las organizaciones y que se utilizan para la creación de interés por la ópera son la asistencia a ensayos generales o pre-generales y las visitas a los teatros y a los entresijos de las producciones operísticas. De la muestra seleccionada, todas las organizaciones ofrecen ambas actividades, normalmente ligadas a los programas didácticos, especialmente con centros escolares o universitarios. También es habitual que este tipo de actividades se ofrezcan a las asociaciones de amigos de la ópera que, a cambio de una cuota anual, colaboran de forma individual con la financiación de las organizaciones. En algunos casos, las actividades se ofrecen de forma gratuita y en otros casos, pagando.

ARBOR Vol. 188754 marzo-abril [2012] 427-440 ISSN: 0210-1963

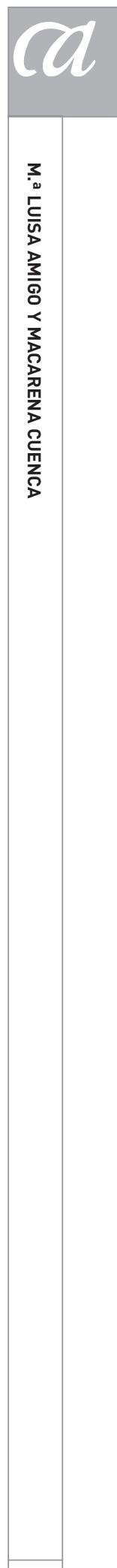

435 
En el caso de las visitas a los teatros encontramos diferentes modalidades. En primer lugar, la visita más básica es la visita cobrada a los lugares públicos del teatro, que tiene un enfoque más bien turistico, en el sentido de que se hace énfasis en el propio edificio, sus diferentes salas y su historia. Hay teatros como, por ejemplo, la Scala de Milán, que tienen incluso un museo en el propio teatro, donde exhiben diferentes objetos, como trajes, vestidos 0 joyas, utilizados en producciones operísticas pasadas.

Después, hay visitas normalmente enmarcadas en los programas didácticos, donde se muestra todo el trabajo que se realiza detrás de la escena y la complicada labor de coordinación que es necesaria para llevar a cabo la representación. Este tipo de visita es muy atractiva y está muy demandada dentro de los programas didácticos debido a su interés, ya que los grupos pueden ver los diferentes talleres de caracterización, sastrería, salas de ensayo, camerinos, maquinaria del escenario, trabajo de iluminación, regiduría, etc. El nivel de explicación durante las visitas se adecúa a las diferentes edades de los grupos visitantes. Además, muchos teatros ofrecen servicios personalizados, en el sentido de que, aparte de adecuar el lenguaje a los grupos, también se adecúa el contenido, en función del interés del grupo o la duración. Así, por ejemplo, el Liceu ofrece una visita teatralizada para alumnos de educación infantil, con el título de "El Misterio de la partitura". La actividad consiste en un juego de pistas, a través del cual se conduce a los alumnos por los distintos espacios del Liceu. Durante el juego, los niños deberán encontrar la partitura desaparecida para que la directora de la orquesta pueda dirigir esa noche la ópera. El Liceu también ofrece diferentes opciones de visitas, donde, por ejemplo, para grupos numerosos, es posible incluso concertar un recital al final de la visita. Otra visita muy interesante que ofrece el Liceu es la visita técnica, dirigida a arquitectos e ingenieros (tanto estudiantes como profesionales graduados) con el objetivo de presentar el edificio del Liceu desde el punto de vista arquitectónico (características de su estructura, instalaciones generales, proyecto acústico, entre otros) sin olvidar su funcionalidad como teatro de ópera.

\subsubsection{Iniciativas dirigidas a familias}

Además del colegio, otra vía de llegar a los niños y adolescentes es a través de sus familias. Para ello, los teatros programan también funciones familiares y llevan a cabo talleres especificos. En cuanto a las funciones familiares, éstas son iguales que las funciones escolares, pero abiertas al público. Habitualmente, se suelen establecer cupos de entradas de adultos, de manera que se prime la venta de entradas infantiles, pero aparte de esto lo demás funciona igual, por lo que no nos vamos a extender más.

Los talleres familiares consisten en unas sesiones didácticas de preparación y sensibilización con la ópera. Lo cierto es que esta actividad está menos extendida, probablemente, porque es más complicada llevarla a la práctica, tanto por temas de espacio como de personal. En el caso de los colegios, muchas de las actividades didácticas se llevan a cabo en los propios centros, mientras que en el caso de los talleres familiares es la organización operistica la que tiene que facilitar el espacio. Algo similar ocurre con el personal, ya que, en los colegios, los profesores actúan en cierto modo de embajadores de la organización y asumen gran parte del liderazgo, mientras que en el caso de las familias todo el peso recae sobre la organización. Por todo esto, no es de extrañar que de la muestra seleccionada, sólo el 50\% de las entidades realicen algún tipo de actividad didáctica dirigida a las familias.

\section{Evaluación de la presencia de los PRINCIPIOS TEÓRICOS EN LAS INICIATIVAS DIDÁCTICAS ANALIZADAS Y PROPUESTA DE POSIBLES LÍNEAS DE ACTUACIÓN}

Una vez revisadas las principales iniciativas didácticas de las organizaciones operísticas seleccionadas, nos disponemos ahora a exponer las conclusiones más relevantes de nuestro análisis. De la misma manera que hemos estructurado los principios teóricos en función de sus ámbitos, también ahora llevaremos a cabo la presente evaluación siguiendo el mismo esquema. Comenzaremos, por tanto, en primer lugar, examinando si los principios fundamentales del ocio se reflejan en los programas didácticos analizados, continuaremos con los principios de educación y finalizaremos con los de estética. Asimismo, y en los casos en los que los principios se vean muy débilmente reflejados, propondremos líneas de intervención orientadas a incorporarlos. De esta forma, se tenderá hacia una mejora en la satisfacción de la experiencia operística de quienes participan en dichas iniciativas educativas. 


\subsection{Principios de ocio}

Los principios fundamentales que caracterizan a cualquier experiencia de ocio son la vivencia, la libertad, la satisfacción y el autotelismo (Cuenca, 2004). En general, todos ellos suelen estar presentes en las iniciativas didácticas, salvo cuando éstas se insertan en los currículos escolares de centros educativos. En este caso, los alumnos no tienen libertad de elección y deben participar en la actividad como si de una clase más se tratase. Además, dicha actividad no tiene, en ese caso, un fin en sí mismo, sino que servirá a los objetivos educativos marcados por el centro. Sin embargo, la introducción de la ópera a través de los colegios es una manera eficaz de llegar a un gran número de niños y adolescentes y de acercarles un género artístico que, en muchos casos, no hubieran tenido oportunidad de conocer de otra manera. Por ello, consideramos que la situación se debe mantener y reconocemos que no siempre la iniciativa didáctica tiene que ser, necesariamente, una experiencia de ocio, sino que puede servir a que ésta pueda llegar a producirse en un futuro. En términos generales, en el caso de las actividades dirigidas al público en general, a las familias o las ofertadas en universidades, sí tienen mayores probabilidades de ser experiencias de ocio, ya que las personas participan en ellas libremente y porque consideran que tienen un valor en sí mismas.

\subsection{Principios de educación}

Como avanzábamos en la fundamentación teórica, los principios que deberían caracterizar a cualquier propuesta educativa son la personalización, la continuidad, el desarrollo, la inclusión y la solidaridad (Cuenca, 2004). Según nuestro análisis, los principios que mejor quedan reflejados en las iniciativas didácticas contrastadas son el desarrollo, la inclusión y la solidaridad, mientras que la personalización y la continuidad son los que presentan mayores oportunidades de mejora.

El principio de desarrollo se cumple, en términos generales, porque se produce un cambio en los participantes. Ellos descubren, experimentan o aprenden algo nuevo $y_{\text {, por }}$ tanto, la actividad no es indiferente, sino que provoca en ellos un proceso de mejora, es decir, un desarrollo personal. Además, como se trata de actividades que no se realizan a diario, éstas suelen ser muy estimulantes y despiertan entusiasmo entre los participantes. En cuanto al principio de inclusión, éste es, precisamente, el motor de los programas didácticos. El público de la ópera ha respondido durante décadas a un perfil muy concreto ${ }^{3}$ y los departamentos didácticos tratan, a través de sus programas, de llegar a otro tipo de público. Por otro lado, aunque todavía no es muy común y, evidentemente, dependerá en gran medida de los recursos que cada organización tenga disponibles, hemos encontrado proyectos específicos dirigidos a colectivos especiales, como puedan ser, por ejemplo, los discapacitados o las minorías étnicas. Por último, el principio de solidaridad queda reflejado en la insistencia de las organizaciones por preservar el género operístico y ponerlo a disposición del disfrute del mayor número de gente posible.

A continuación, abordamos los dos principios que consideramos se ven en menor medida reflejados en los programas analizados, el principio de personalización y el de continuidad. En primer lugar, queremos manifestar expresamente que somos conscientes de que hacer realidad en su totalidad el principio de personalización es una utopía. El coste sería tan alto que haría completamente imposible la puesta en marcha de un objetivo tan ambicioso. Sin embargo, esto no significa que debamos ignorarlo por completo, sino que se debiera convertirse en un ideal al que las propuestas educativas deberian tender y en cuyo camino cada cual debiera buscar su punto de equilibrio. Este punto de equilibrio tendrá que poner en relación, en un lado de la balanza, la personalización, la satisfacción de los participantes y la calidad del servicio, y en el otro, la productividad y el coste de la actividad. En la aplicación del principio de continuidad también nos encontraremos con un dilema, que cada organización, en función de sus recursos y sus propias necesidades, deberá resolver de distinta manera. La continuidad promueve la acción educativa a largo plazo y con una coherencia de objetivos y acciones a lo largo del tiempo. Esto significa establecer vínculos, más allá de sesiones puntuales y, por tanto, dedicar esfuerzos y recursos a un mismo colectivo de personas. El dilema aparece, precisamente, en este punto, ¿dónde encontramos el equilibrio entre llegar al mayor número de gente posible y tener un mayor impacto en las personas alcanzadas, gracias a acciones educativas continuadas en el tiempo? Evidentemente, no hay una única respuesta y será, de nuevo, cada organización quien deberá marcar los límites. Tras estas reflexiones, expondremos algunos ejemplos concretos y algunas propuestas de mejora en relación a estos dos principios.

ARBOR Vol. 188754 marzo-abril [2012] 427-440 ISSN: 0210-1963 
Dentro de las iniciativas analizadas, algunas de ellas cuentan ya con ciertos rasgos de personalización, especialmente las que se dirigen a colectivos concretos. Por ejemplo, hay visitas a la carta o sesiones modulables en función de los intereses de cada grupo. Sin embargo, esto no suele producirse en las actividades ofertadas al público en general. Probablemente, la diferencia radique en que estas últimas sean actos más multitudinarios $y$, además, se desconozca de antemano el perfil y las necesidades de los asistentes. En estos casos, cada organización deberá fijar cuál es el número máximo de gente admitida, teniendo en cuenta que a menor tamaño del grupo, más fácil será la personalización y deberá afrontar, por tanto, el dilema del equilibrio aludido anteriormente. En estos casos, ante el desconocimiento de los asistentes, la personalización deberá tratarse de abordar sobre la marcha, a través de la participación, promoviendo las intervenciones del público. En el caso de las sesiones dirigidas a colectivos concretos (colegios, universidades, etc.), sería recomendable el contacto previo con personas responsables del grupo, que pudieran actuar a modo de portavoces, como, por ejemplo, los profesores. Estas personas debieran funcionar como enlaces entre su grupo y la organización operística. Así, por un lado transmitirian a la organización las necesidades del grupo y, por otro lado, podrian intervenir en las propias sesiones, personalizando aspectos más concretos, gracias a su conocimiento de todos los participantes. Por ello, consideramos primordial que las organizaciones operisticas dediquen un tiempo a entrevistarse con estos enlaces y a involucrarles en la planificación de las sesiones.

En cuanto a la información disponible en internet, es cierto que cada persona puede acceder a los contenidos que más le interesen y que, por tanto, podríamos afirmar que la personalización está presente de alguna manera. Sin embargo, en muchos casos, especialmente en las organizaciones más modestas, los contenidos son limitados y bastante estándares (ficha técnica, argumento, fotos de la producción y una breve reseña histórica). En ningún caso parece que el tipo de información publicada parta del conocimiento y las necesidades de los internautas. En este sentido, una línea de trabajo podría ser el establecimiento de un proceso de comunicación entre la organización y los internautas para recoger las necesidades de información de estos últimos. Lo ideal sería involucrarles, incluso, en la creación de los contenidos, por ejemplo, a través de acuerdos de colabora- ción con colectivos a los que puedan pertenecer. Pensemos, por ejemplo, que un aspecto interesante de todas las producciones es el vestuario. La organización podría llegar a un acuerdo con una escuela de diseño que acercara a sus alumnos la ópera a partir del vestuario de una producción concreta, de forma que, luego, fueran ellos mismos quienes escribieran un texto relativo a este tema y que fuera publicado en la web de la organización.

En definitiva, de nuestro análisis se desprende que gran parte de las iniciativas didácticas que son llevadas a cabo por las organizaciones operísticas son motivadoras del interés grupal y proponen acciones para un grupo, bien en el caso de los escolares o en los adultos. Bajo nuestro punto de vista sería aconsejable que se tuvieran en cuenta algunas acciones que posibilitaran la acción grupal con la participación personal. En este sentido, la calidad de la experiencia receptiva podría verse favorecida gracias a acciones que condujeran a que cada persona sea consciente de su capacidad creativa, suscitando en ella una reflexión.

El principio de continuidad también se cumple en parte en determinados casos, especialmente, cuando se trata de iniciativas dirigidas a colectivos concretos y no al público en general. Como hemos podido observar a lo largo de la descripción de los programas, algunos de ellos tienden a prolongarse en el tiempo, como por ejemplo los dirigidos a estudiantes de secundaria, cuyo contenido se centra en la creación de una ópera por parte de los propios alumnos. Sin embargo, muchas otras sesiones consisten en encuentros puntuales y lo mismo ocurre en las charlas de introducción a la ópera o en los encuentros con artistas. En estos casos, la posible línea de intervención podría venir de la mano de la instauración de la figura de un presentador o moderador que se responsabilizara de dar continuidad a los distintos eventos. Se podría establecer una estructura común del contenido de las charlas, de forma que los conferenciantes se ajustaran a ella y, asi, se produjera una coherencia y una continuidad entre los diferentes encuentros. Por otro lado, éstos se podrían grabar y publicarlos en internet, de manera que, además de contribuir a una mayor difusión, estarian a disposición de los intervinientes para su consulta previa. Así, la revisión de este material podría ayudar a los conferenciantes a dar continuidad a su exposición, a pesar de no haber estado presentes en eventos anteriores. 


\subsection{Principios de estética}

Finalmente, los principios teóricos que hemos identificado desde la teoría de la estética son la actitud personal, la participación, el descubrimiento, la comprensión y la satisfacción. Desde el punto de vista del descubrimiento pensamos que las acciones didácticas se sostienen sobre este factor. Ahora bien, quizá, vinculando este aspecto con la participación personal y teniendo en cuenta la necesidad de respetar el proceso temporal, nos parecería apropiada una intervención procesual que combinara la acción grupal con la participación personal. Tanto para las intervenciones a largo plazo, como para aquellas que se realizan teniendo como eje central la asistencia a la representación, deberían tratar de fomentar una mirada experiencial motivando la incorporación de la persona a la experiencia. Si las acciones se orientan a este segundo caso, nos parece estéticamente formativo que antes de la representación se lleven a cabo algunas sesiones, para facilitar la experiencia más plena en la sala y que finalmente se dé la oportunidad de comentarla en otra sesión posterior. Así podríamos esbozar tres fases, preparatoria, de realización de la experiencia en el teatro y una posterior, de evaluación y comentario grupal.

Todas las intervenciones educativas deberian facilitar la personalización, favoreciendo la imaginación, la estimulación hacia la riqueza sensorial de la obra, así como la clarificación de los intereses y expectativas de cada uno. Las puestas en escena actuales tienen una gran riqueza sensible que se debería transmitir, destacando el juego de imágenes de la escena, la iluminación, el vestuario, los códigos visuales, que pueden tener un valor simbólico, o la estructura organizativa de los coros $u$ otros aspectos rele- vantes. Estos factores estarian orientados a desarrollar las habilidades necesarias para profundizar en el conocimiento de la obra, del mundo que presenta, la historia. Además se podría recrear el argumento en el momento actual, relacionándolo con situaciones reales o acontecimientos sociales, proporcionando claves de lectura y explicitando los símbolos. Todo ello con vistas a la actualización de la misma, para que se comprenda desde la actualidad que vive el espectador y no como arqueología. Tras cualquier proceso se debe propiciar la reflexión que supone una evaluación de la experiencia. El espectador tendrá una visión global de la misma y descubrirá las implicaciones del mundo cognoscitivo y de valores que ha experimentado. Será enriquecedor para el grupo que las valoraciones personales se comuniquen a los demás.

\section{Reflexión final}

Todas las iniciativas didácticas que se están llevando a cabo en las instituciones responsables son, sin duda, positivas y ayudan a que la experiencia estética sea más rica. Favorecen la recepción de la ópera y animan a los participantes a introducirse en el mundo operístico. La aproximación analítica que hemos llevado a cabo parece apuntar especialmente la carencia de una implicación personal en las actividades acometidas, así como una débil continuidad temporal de las mismas. Las líneas de actuación destinadas a hacer realidad estos principios teóricos son complicadas y costosas. Por ello, cada organización deberá valorar dónde situar el punto de equilibrio entre ambos aspectos, en función de sus recursos y necesidades.

\section{NOTAS}

1 Al mencionar este tipo de actividades, nos referimos a eventos extraordinarios, como la colocación de pantallas gigantes en determinados lugares de la ciudad, la celebración

Recibido: 13 de mayo de 2011 Aceptado: 14 de julio de 2011 de dias de puertas abiertas en los teatros, etc.
2 La Cenerentola es una ópera de Rossini cuyo argumento es el cuento de la cenicienta.

3 En términos generales, el perfil del público de la ópera se corresponde con una persona mayor de 45 años, con estudios universitarios, de status social alto y de procedencia urbana (Ministerio de Cultura, 2007). 


\section{BIBLIOGRAFÍA}

Alier, Roger (2004): ¿Qué es esto de la ópera?: introducción al mundo de la lírica, Barcelona, Ma Non Troppo.

Amigo Fernández de Arroyabe, M. ${ }^{a}$ Luisa (2000): El arte como vivencia de ocio, Bilbao, Universidad de Deusto.

Amigo Fernández de Arroyabe, M. ${ }^{a}$ Luisa (2008): "La experiencia de ocio estético", en Monteagudo Sánchez, M. J. (ed.): La experiencia de ocio: una mirada científica desde los estudios de ocio, Bilbao, Universidad de Deusto, pp. 111-135.

Andréu, Jaime (2001): Las técnicas de Análisis de Contenido: Una revisión actualizada, Sevilla, Centro de Estudios Andaluces.

Csikszentmihalyi, Mihaly (2008): Fluir. Una psicología de la felicidad, Barcelona, Kairós.

Cuenca Cabeza, Manuel (2000): Ocio humanista: dimensiones y manifestaciones actuales del ocio, Bilbao, Universidad de Deusto.
Cuenca Cabeza, Manuel (2004): Pedagogía del ocio: modelos y propuestas, Bilbao, Universidad de Deusto.

Davis, Ken (1988): Rehearsing the Audience, Urbana, IL, ERIC Clearinghouse on Reading and Communication Skills and the National Council of Teachers.

Dewey, John (1949): El arte como experiencia, México, FCE.

Doublet, Gérard (2001): Les publics d'opéra en France. Etude realisée pour la réunion des théâtres lyriques de France, Material no publicado.

Doublet, Gérard (2003): "Opéra: nouveau public, nouvelles pratiques", en Donnat, 0. y Tolila, P. (eds.), Le(s) public(s) de la culture, Paris, Presses de Sciences Po, pp. 215-234.

Dufrenne, Mikel (1982): Fenomenología de la experiencia estética, Valencia, Fernando Torres.

Eco, Umberto (1979): Obra abierta, Barcelona, Ariel.

Gadamer, Hans Georg (1996): Estética y hermenéutica, Madrid, Tecnos.

Gadamer, Hans Georg (1977): Verdad y método, Salamanca, Sígueme.
Hospers, John (1980): Significado y verdad en las artes, Valencia, Fernando Torres.

Jauss, Hans Robert (1986): Experiencia estética y hermenéutica literaria. Ensayos en el campo de la experiencia estética, Madrid, Taurus.

Jiménez, José (ed.) (1998): El nuevo espectador, Madrid, Visor-Fundación Argentaria.

López Quintás, Alfonso (1998): Estética de la creatividad, Madrid, Rialp.

López Quintás, Alfonso (2005): Estética musical, Valencia, Rivera Editores.

Malhotra, Naresh K. (2004): Investigación de mercados. Un enfoque aplicado (Cuarta edición ed.), México, Pearson Educación.

Ministerio de Cultura (2007): Encuesta de hábitos y prácticas culturales 20062007. Obtenido de http://www.mcu. es/estadisticas/MC/EHC/2006/Presentacion.html (última consulta: 29 de septiembre de 2010).

Molinuevo, José Luis (1998): La experiencia estética moderna, Madrid, Síntesis.

Plazaola, Juan (1991): Introducción a la Estética, Bilbao, Universidad de Deusto. 